\title{
LA IDEA DE REPRESENTACION EN LA OBRA POLITICA DE NICOLAS DE ORESME
}

Antonio D. Tursi

SINTESE - No presente trabalho é examinado o conceito de "representação" em duas obras de Nicolau de Oresme. No De moneta, o pensador medieval faz pequenas referências ao poder de decisão do povo em questões monetárias. Anos mais tarde, ao traduzir e comentar a Política de Aristóteles, retoma a noção de Marsílio de Pádua a respeito da multidão como legislador, mas define a multidão não como o povo, mas como a congregação de todos os príncipes ou oficiais, entre os principais cidadãos.

PALAVRAS-CHAVE - Filosofia política medieval, conceito de representação, povo, multidão, soberania parlamentar.
ABSTRACT - This article examines the concept of "representation" in two works of Nicholas of Oresme. In De moneta this medieval thinker makes little references to the decision power of people in monetary matters. Some years later, translating and commenting on Aristotle's Politics, he takes up again the notion of Marsilius of Padua regarding the crowd as legislator, but he defines the crowd not as people but as a gathering of the totality of princes or officers among the chief citizens.

KEY WORDS - political philosophy in Middle Ages, concept of representation, people, crowd, parliamentary sovereignty.

Nicolás de Oresme en dos períodos de su vida, sea por encargo o por propia inquietud, se abocó a cuestiones de filosofía política. El primero hacia 1355-1360 cuando compuso un tratado de política monetaria conocido como De moneta; el segundo hacia 1370-1375 cuando tradujo del latín al francés y comentó las obras de filosofía práctica de Aristóteles. Nosotros nos proponemos analizar la idea de representación que vincula a ambas obras, a fin de demostrar que tal noción sólo esbozada en el De moneta es retomada, aclarada y ejemplificada especialmente en su Livre de Politiques de Aristóteles. Así pues, aunque, a las claras, el De moneta sea un texto de economía y que toda consideración política que haga allí Oresme queda restringida a criterios de su politica monetaria, con todo resumiremos primero las notas que encontramos hacen a la comunidad y al poder de ella frente al del príncipe y después las confrontaremos con la idea de representación que esboza Oresme en su comentario a la Política.

* Universidad de Buenos Aires.

\begin{tabular}{|l|l|l|l|l|l|}
\hline VERITAS & Porto Alegre & v. 43 & $\mathrm{n}^{0} 3$ & Setembro 1998 & p. $665-669$ \\
\hline
\end{tabular}


El Tratado acerca del origen y la naturaleza, derecho y cambios de las monedas o en forma abreviada De la moneda tiene en su forma definitiva 26 capitulos más un proemio en el cual Oresme declara su objetivo: combatir el poder omnimodo que se arrogan los príncipes sobre las monedas, señalar sus males y proponer soluciones. Los 26 capítulos se dividen en dos partes. Una primera que va del 1 al 16 y trata del origen, fin y cambios naturales de las monedas, de acuerdo, como ya lo declaró en el proemio, con la filosofía de Aristóteles, exactamente según los capitulos 9 al 11 del libro I de la Política, dedicados a la crematística. La segunda parte va del capítulo 17 al 24 y trata de algo que Aristóteles no conoció, de una "novedosa invención" (cap. 18) ${ }^{1}$ porque "en su tiempo tal malicia todavía no había sido inventada" (cap. 17): de un cambio antinatural de la moneda, la alteración o devaluación. Oresme en estos capitulos pone al descubierto el recurso de la devaluación de la moneda hecho por los príncipes, puntualiza sus perjuicios económicos, políticos y sociales y la licitud e ilicitud de la alteración. Finalmente los capítulos 25 y 26 hacen las veces de apéndice político de la obra y giran en torno a las distinciones clásicas entre monarquía y tiranía.

Entre 1355 y 1360 Nicolás de Oresme hace tres versiones del De moneta. Las dos primeras en latín. La segunda de 1358 con 26 capítulos difiere de la primera de 1355 con 23 capitulos en que Oresme abre la posibilidad, negada en la primera, de devaluar la moneda como método rápido y seguro para obtener una urgente e ingente cantidad de dinero. L. Guillard² encuentra en ello una "lógica histórica de la doble redacción (antes/después de 1356)" porque, precisamente, a las revueltas sociales hay que añadir el desastre de Poitiers en septiembre de 1356, cuando Juan el Bueno es hecho prisionero de los ingleses y su rescate es pactado en tres millones de escudos de oro. En el capitulo 22 Oresme determina que una devaluación bien podría aplicarse extraordinariamente "en caso de guerra o para el rescate del principe en cautiverio". Finalmente, el mismo Oresme traduce esta segunda versión latina al francés, a pedido del propio Carlos V, amplía el proemio y agrega unas breves acotaciones. No sabemos a ciencia cierta si Carlos $V$, siendo aún el Delfín tuvo a Oresme como preceptor, pero lo cierto es que una vez en el trono de Francia, lo convoca para colaborar y que a partir de 1360, por inspiración de la obra de Oresme o por casualidad, comienza el período de estabilidad monetaria más largo del siglo XIV para Francia. ${ }^{3}$

1 Seguimos nuestra versión en NICOLAS DE ORESME, Tratado sobre la moneda. Introducción, traducción y notas de H. BASBUS y A.D. TURST, Editorial Machi, Bs. As., 1998. Ediciones modernas del Tratado: Nicolaus Oresme, Tractatus de origine, natura, iure et mutationibus monetarum, ed. L.M.R. Woloski, París 1864, reimpr. Roma 1969 y Ginebra 1976. Nicolaus Oresme, Traktat über Geldawertungen, ed. E. Schorer, Jena 1937. Nicholas Oresme, The De moneta and English Mint Documents, ed. Ch. Johnson, Londres 1956. Nicolas Oresme, Traité des monnaies et autres écrites monétaires du XIVè. siècle, ed. Cl. Dupuy, Lyon 1989.

2 "Nicole Oresme, économiste", Revue historique, 112, 279 (1988), p. 4.

3 cf. op. cit., loc. cit. y D. MËNJOT, "La politique monétaire de Nicolas Oresme", Actes du Colloque Oresme: Nice 1983, París 1987, p. 185. 
Ahora bien, del texto podrían extraerse las siguientes notas respecto de su concepción de la comunidad:

1) Para Oresme, una originaria y natural apropiación de bienes por parte de los hijos de Adán llevó a los hombres a ser propietarios (cap. 1).

2) Por el carácter mismo de esa apropiación y por la diversidad de regiones no hubo, de hecho, una adquisición favorable y equitativa de bienes para todos (cap. 1).

3) De ello se siguió la necesidad del trueque o intercambio de mercaderías (cap. 1).

4) Mas por ser ese intercambio en algunos casos dificultoso, los hombres se las ingeniaron e inventaron las monedas (cap. 1).

Oresme no explicita si ese trueque es el que hizo que los hombres se agruparan en comunidades, sino simplemente acota que dicha forma de comercio fue tiempo después instituida en las ciudades. Así pues, la aparición de la moneda encuentra a las ciudades ya establecidas y compuestas de individuos propietarios. La primera conclusión de Oresme respecto de la moneda es:

5) que la moneda es un producto comunitario, una invención de la sagacidad humana, que sirve como instrumento para facilitar la permutación de las riquezas naturales (cap. 2) y muy apto para el comercio (cap. 3). En el Livre de Politiques agregará que es un medio ordenado para el bien vivir y no un fin en sí mismo. ${ }^{4} \mathrm{Y}$ la segunda conclusión:

6) que la moneda pertenece a la comunidad y a todos sus individuos, y más específicamente a aquellos que poseen riquezas naturales (cap. 6).

En su concepción de riqueza natural Oresme no sólo está pensando en bienes y posesiones, sino también en el trabajo del hombre libre (cap. 6) que es cambiado por moneda o salario justo.

Aunque no determine el origen de la comunidad, Oresme sí la describe en sus partes que equipara a una división del trabajo. Así hay una parte de ia comunidad, la mejor y necesaria, que se dedica a negocios honorables y útiles (cap. 21), esto es al crecimiento o producción de las riquezas naturales y a su tratamiento, administración o comercio, a saber: los hombres de la Iglesia, los jueces, los militares, los agricultores, los comerciantes y los artesanos. Hay otra parte, en cambio, la peor, con cuyos negocios obtiene un vil beneficio (cap. 21) y es la que lucra con la moneda: el arte cambiario, custodia o comercio monetario; la usura y la alteración. Resulta significativo notar que Oresme no siga aquí la condena por parte de Aristóteles del arte cambiario y la usura, a pesar de que las describa con iguales términos que el estagirita, sino que diga que son "casi" innecesarias (cap. 21), pues hasta cierto punto son permitidas (cap. 18), como lo son también los lupanares públicos (cap. 18). Entonces, como la moneda pertenece a la comunidad, la comunidad debe:

7) establecer todo lo relativo a la política monetaria; fabricar moneda, legisiar sobre ella, ejecutar la legislación y observar el cumplimiento (caps. 5-21, passim), y lo que la comunidad decida es una "cierta ley y firme ordenanza" (cap. 8). Incluso

4 A.D. MENUT, Maistre Nicole Oresme, Le Livre de Politiques d' Aristote, Philadelphia, Transactions of the American Philosophical Society, 1970, p. 63. 
puede delegar en una persona pública, el príncipe, p.e., esa su función ejecutiva, reservándose para sí la legistativa y de control. El príncipe, en este caso, es solo un ejecutor de una orden pública emanada de la comunidad (cap. 24).

Este proceder es propio, pues, de una comunidad que conoce sus derechos, naturalmente libre y que, por ello, nunca a sabiendas se sometería al yugo de un poder tiránico (cap. 24).

Oresme, con todo, no establece en el De moneta de qué manera la comunidad legisla sobre la moneda, si toda ella en asamblea, si elige un cuerpo colegiado que la represente... En toda la obra siempre Oresme refiere el término "communitas", sólo una vez (cap. 24) lo equipara a "populus"; pero en ocación de analizar el hecho de que el principe pueda fingir alguna necesidad para devaluar la moneda (cap. 24), Oresme restringe la acepción del término: es "la comunidad o su parte de mayor valia" la que debe analizar la necesidad esgrimida por el príncipe, dice Oresme recurriendo al famoso giro de Marsilio de Padua. ${ }^{5}$ Mas aquí tampoco especifica en qué consiste la parte de mayor valía.

Brevemente, entonces, según el De moneta, hay en la comunidad una base privada de propietarios-trabajadores de desiguales recursos económicos. Gracias a esta desigualdad se da para Oresme una cierta armonía en la república, como en un coro se necesita una proporcionada y mesurada desigualdad de voces (cap. 25). Estos propietarios, por derecho natural, deciden y controlan sea ellos mismos sea sus representantes o su parte de mayor valía la legislación en política monetaria, la cual bien podría ser ejecutada por el príncipe.

\section{II}

Entre 1370 y 1375 Nicolás de Oresme traduce y comenta la Política, la Etica y la Económica de Aristóteles, a pedido y dedicadas al rey Carlos V de Francia. La situación política y social es muy diferente a la de diez años atrás. El Valois ya está consolidado en el trono y con el apoyo de su Consejo lleva, de un lado, una política cultural que se ha considerado como un verdadero renacimiento franco y, de otro, comienza su contraataque al ocupante inglés.

En su comentario a la Política, precisamente, Oresme retoma esa noción de representación que en el De moneta no había quedado suficientemente explicitada y en varios pasajes repite casi textualmente la fórmula marsiliana. ${ }^{6} \mathrm{Si}$ antes la comunidad legislaba sobre la moneda por ser su propietaria, ahora al encontrarse con la afirmación aristotélica de que a todos incumbe juzgar sobre una cosa por el solo hecho de usarla (Politica III, 11, 1282 a 17-23), Oresme explicita que en base a esta razón en un libro titulado Defensor de la Paz (I, xii, 3) se alega que las leyes humanas positivas deben ser hechas, promulgadas y corregidas con la anuencia de la autoridad y el consentimiento de toda la comunidad o su parte de mayor valía (p. 137), y un poco más adelante vuelve a afirmar que la multitud debe tener el dominio en los asuntos más importantes como son la corrección y la elección de

5 Sobre el uso de este giro marsiliano y la utilización del prohibido Defensor Pacis por parte de Nicolás de Oresme, véase nuestro artículo "Communitas aut valencior pars. Un giro marsiliano en Nicolás de Oresme y la composición del De moneta", Patristica et Mediaevalia, XVIII (1997).

6 cf. Livre des Politiques, ed. cit., p. 109, p. 137 dos veces, y p. 241. 
los príncipes (loc. cit.). Así pues, si en el De moneta el alcance del poder de la comunidad o su parte de mayor valía quedaba circunscripto a la política monetaria, ahora, en cambio, en el Livre des Politiques es ampliado ese poder a la legislación en general.

Tampoco en su comentario menciona Oresme de qué manera se conforma la multitud o su parte de mayor valía, pero, a diferencia del De moneta, se vale de dos ejemplos que bien podrían servir de analogía. En el primero (p. 274) sostiene que la multitud no es el pueblo, sino la congregación de todos los príncipes u oficiales de entre los principales ciudadanos, como sucede con los maestros de la Universidad de París. En el segundo (p. 274-5) remite a las antiguas prácticas de los concilios eclesiásticos en los cuales se reunían los principales obispos para determinar, junto con el papa, la legislación de la Iglesia. ${ }^{7}$ Así, entonces, Oresme está pensando en un cuerpo legislativo y representativo de los estados del reino al cual el príncipe acataría y respecto del cual solo cumpliria las funciones de ejecutor. Este cuerpo se reuniría (p. 274-5) o bien por medio de la decisión de un príncipe u oficial que así lo decida o bien por medio de una ley que estipulase en qué casos y por qué cuestiones.

A. Black ${ }^{8}$ encuentra en el Livre des Politiques el primer enunciado sistemático de un parlamento soberano, al cual identifica con los representantes de los Estados Generales que conformaban el Consejo del Valois. Oresme, sigue Black, utiliza asi el lenguaje aristotélico de una manera cuasi parlamentaria para aconsejar una forma conveniente de gobernar. J. Dunbabin ${ }^{9}$ identifica también la parte de mayor valia con la aristocracia, y, a su criterio, Oresme fuerza el texto aristotélico referido a la participación popular dentro de un estado hacia la supremacía legislativa del pueblo o su parte de mayor valía.

Nosotros creemos que Oresme realiza una sintesis entre algunos pasajes referidos a la soberanía popular que lee en Aristóteles y un cuerpo representativo con poderes legislativos y de control que encuentra en el Defensor de la paz de Marsilio de Padua, a fin de sustentar teóricamente una situación que anhelaba para el reino de Francia: un cogobiemo de rey y consejo representativo de la aristocracia. Oresme toma el Defensor de la paz como un comentario más a la Política aristotélica y utiliza algunos pasajes del texto de Marsilio a fin de actualizar la obra aristotélica, de demostrar su aplicabilidad, aún casi veinte siglos después de ser escrita, a los integrantes del Consejo de Carlos V y la nobleza en general, principales lectores de sus comentarios.

7 cf. M. GRIGNASCHI, "Nicole Oresme et son commentaire à la Politique d' Aristote", Album Cam. I. Studies Presented to the Intemational Committe for the History of Representative and Parliamentary Institutions, 23, Lovaina, 1960, p. 119.

8 El pensamiento politico en Europa, 1250-1450, Cambridge University Press, Cambridge, 1996, pp. $260-1$.

9 "The reception and interpretation of Aristotle's Politics", The Cambridge History of Later Medieval Philosophy, Cambridge, 1982, p. 732. 